13

\title{
Микроструктура областей воздействия искрового разряда на поверхность плоского медного электрода в воздухе в промежутке „острие-плоскость“
}

\author{
(C) А.А. Тренькин, ${ }^{1}$ В.И. Карелин, ${ }^{1}$ Ю.М. Шибитов, ${ }^{1}$ О.М. Блинова, ${ }^{1}$ И.С. Ясников ${ }^{2}$
}

${ }^{1}$ Российский Федеральный ядерный центр

Всероссийский научно-исследовательский институт экспериментальной фризики, 607190 Саров, Россия

${ }^{2}$ Тольяттинский государственный университет, 445020 Тольятти, Россия

e-mail: trenkin@ntc.vniief.ru

(Поступило в Редакцию 11 января 2017 г.)

С использованием сканирующего электронного микроскопа исследована микроструктура областей воздействия искрового разряда на поверхность плоского медного электрода в воздухе атмосферного давления в промежутке „острие-плоскость“ как при положительной, так и при отрицательной полярностях острия. Установлено, что области воздействия представляют собой округлые пятна или группы пятен с диаметрами отдельных пятен от 20 до $200 \mu \mathrm{m}$. Обнаружено, что пятна обладают внутренней пространственной структурой в виде совокупности концентрических колец. Кольца представляют собой скопления большого числа микрократеров диаметрами $0.1-1 \mu \mathrm{m}$.

DOI: 10.21883/JTF.2017.09.44920.2166

\section{Введение}

В ряде практических задач (создание газоразрядных коммутаторов и плазмохимических реакторов, нанесение тонких покрытий, модификация поверхностей и т. п.), связанных с реализацией газовых разрядов, весьма важным является вопрос воздействия разряда на электроды, определяющего характер и степень их эрозии. Исследования в этом направлении ведутся достаточно давно [1-4], однако, несмотря на огромное количество работ, посвященных данной тематике, ряд явлений до сих пор мало изучен. Одним из них является наличие микроструктуры отпечатков (автографов) токовых каналов наносекундных и микросекундных разрядов в плотных газах в режиме однократных импульсов [5-16]. Автографы таких разрядов на поверхности плоского электрода представляют собой скопления (до 1000 и более) эрозионных микрократеров диаметрами $1-30 \mu \mathrm{m}$. Поверхностная концентрация микрократеров в автографе составляет $2 \cdot 10^{2}-5 \cdot 10^{3} \mathrm{~mm}^{-2}$. Микроструктура обнаружена в довольно широком диапазоне экспериментальных условий, включая различные: типы разрядов, газы и их смеси, формы и материалы электродов и их покрытия [5-16]. Полученные результаты свидетельствуют о крайне неоднородном пространственном распределении энерговыделения в таких разрядах.

Следует отметить, что исследование микроструктуры автографов в работах [6-16] осуществлялось с использованием оптической микроскопии, что в известной мере ограничивает возможность получения детализированных пространственных характеристик.
В работе [17] микроструктура автографов субмикросекундного искрового разряда в воздухе атмосферного давления в промежутке „острие-плоскость“ была исследована с использованием сканирующего электронного микроскопа. Здесь изучалось воздействие разряда на поверхность плоского электрода, изготовленного из нержавеющей стали марки 316L. В результате были обнаружены микронная и субмикронная структуры автографа в виде микрократеров диаметрами 0.3-5 $\mu \mathrm{m}$ и дорожек. Установлено, что все микрократеры расположены на дорожках, образующих сложную сетчатую структуру. При этом поверхностная концентрация микрократеров составляет $(2-5) \cdot 10^{4} \mathrm{~mm}^{-2}$, что существенно превосходило зарегистрированные ранее значения [6-16].

Настоящая работа является продолжением начатых в [17] исследований областей воздействия разряда на поверхность плоского электрода с использованием электронной микроскопии. Здесь для определения влияния свойств материала плоского электрода на параметры микроструктуры автографа разряда в качестве материала электрода использована медь.

\section{1. Экспериментальная аппаратура и методика}

Эксперименты проводились на стенде, включающем генератор импульсов напряжения (ГИН), разрядный промежуток и диагностическую аппаратуру (рис. 1). ГИН имел в своем составе биполярный источник статического напряжения, формирующую кабельную линию, состоящую из 6 параллельно соединенных отрезков кабелей длиной $20 \mathrm{~m}$ и волновым сопротивлением $50 \Omega$ 


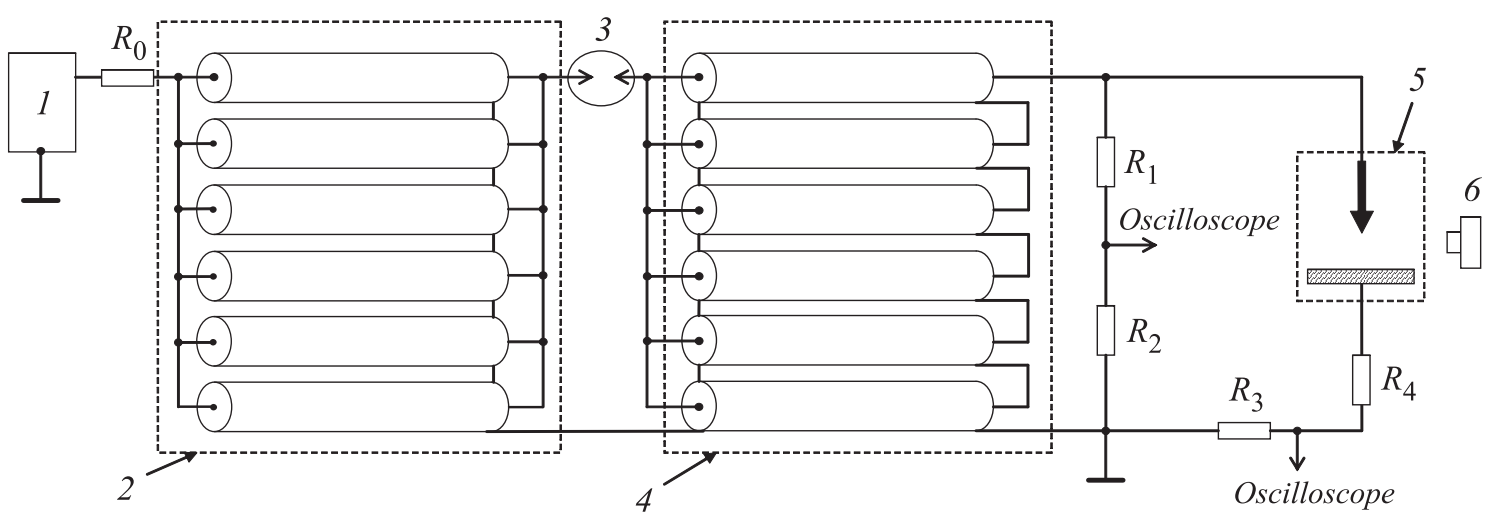

Рис. 1. Схема экспериментального стенда: 1 - биполярный источник статического напряжения, 2 - формирующая кабельная линия, 3 - разрядник, 4 - трансформатор на отрезках коаксиальных кабелей, 5 - разрядный промежуток, $6-$ фотоаппарат, $R_{0}=10 \mathrm{M} \Omega$ - зарядный резистор, $R_{1} / R_{2}-$ резистивный делитель, $R_{3}=10 \Omega$ - резистивный токовый шунт, $R_{4}=40 \Omega-$ ограничивающий резистор.

каждый, разрядник и трансформатор, выполненный на 6 отрезках кабельных линий длиной 20 m и сопротивлением $50 \Omega$ каждый. На резистивной нагрузке ГИН обеспечивал импульсы амплитудой до $30 \mathrm{kV}$ как отрицательной, так и положительной полярности, с фронтом нарастания 10-20 ns и длительностью по основанию $250 \mathrm{~ns}$.

Разряд формировался в промежутке „острие-плоскость“ с межэлектродным расстоянием $3 \mathrm{~mm}$. Электрод-острие длиной $5 \mathrm{~cm}$ и диаметром $15 \mathrm{~mm}$ изготовлен из алюминиевого сплава. Угол при вершине острия $80^{\circ}$, радиус кривизны $0.2 \mathrm{~mm}$. В качестве плоского электрода использовалась пластина из меди марки M1 по ГОСТ $859-78$ толщиной $2 \mathrm{~mm}$ и размером $65 \times 20 \mathrm{~mm}$.

Рабочая поверхность плоского электрода полировалась до зеркального блеска $\left(R_{a}=0.10-0.15 \mu \mathrm{m}\right.$ по ГОСТ 2789-73), после чего электрод отжигался в вакуумной печи в течение $1 \mathrm{~h}$ при температуре $700^{\circ} \mathrm{C}$.

Для получения автографов токовых каналов использовались две идентичные пластины соответственно для импульсов положительной и отрицательной полярностей, подаваемых на острие. На каждую пластину подавалось несколько импульсов напряжения. При этом после каждого импульса осуществлялась сдвижка плоского электрода вдоль его длинной центральной линии, так, чтобы автографы, оставляемые разрядом в каждом отдельном импульсе, были пространственно отделены.

В экспериментах регистрировались напряжение на промежутке, ток разряда и интегральное свечение разряда. Измерение напряжения $U$ на разрядном промежутке осушествлялось резистивным делителем, тока $I$ резистивным шунтом. Регистрация напряжения и тока выполнялась с помощью цифрового осциллографа с полосой пропускания $500 \mathrm{MHz}$. Разряд фотографировался цифровым фотоаппаратом в направлении, перпендикулярном оси электрода-острия.

Исследование морфологии поверхности плоского электрода осуществлялось с помощью сканирующего электронного микроскопа ZEISS SIGMA в режиме детектирования вторичных электронов (детекторы SE и InLens) и обратно рассеянных электронов (детектор AsB). Отметим специфику различий изображений, получаемых с использованием этих детекторов. Изображение объекта, полученное с помощью детектора вторичных электронов, отличается равномерным освещением образца, ярко окаймленными краями и хорошо выраженной топографией, при этом контраст материала (зависимость от атомного номера) слабо выражен. В отличие от этого, изображение объекта, полученное с помощью детектора обратно рассеянных электронов, показывает четко выраженные различия материалов по атомному весу, но аспекты морфологии поверхности отображаются слабее, чем во вторичных электронах [18]. Следует также отметить, что детектор SE обладает меньшей чувствительностью по сравнению с детектором InLens, поэтому основная часть изображений получена с использованием последнего.

\section{2. Экспериментальные результаты и их обсуждение}

На рис. 2 представлены типичные осциллограммы напряжения $U$ и тока $I$ разряда для положительной полярности острия. Осциллограммы для отрицательной полярности имеют инвертированный вид и не содержат существенных отличий формы по сравнению с осциллограммами для положительной полярности. Установлено, что при фиксированной полярности осциллограммы от импульса к импульсу не претерпевают существенных изменений. Небольшое отличие наблюдается только в длительности задержки между моментами подачи импульса напряжения и появления тока разряда. Средняя задержка для положительной полярности составляет $50 \mathrm{~ns}$, для отрицательной - $30 \mathrm{~ns}$.

На рис. 3 представлена характерная фотография свечения разряда. Структура свечения канала разряда 


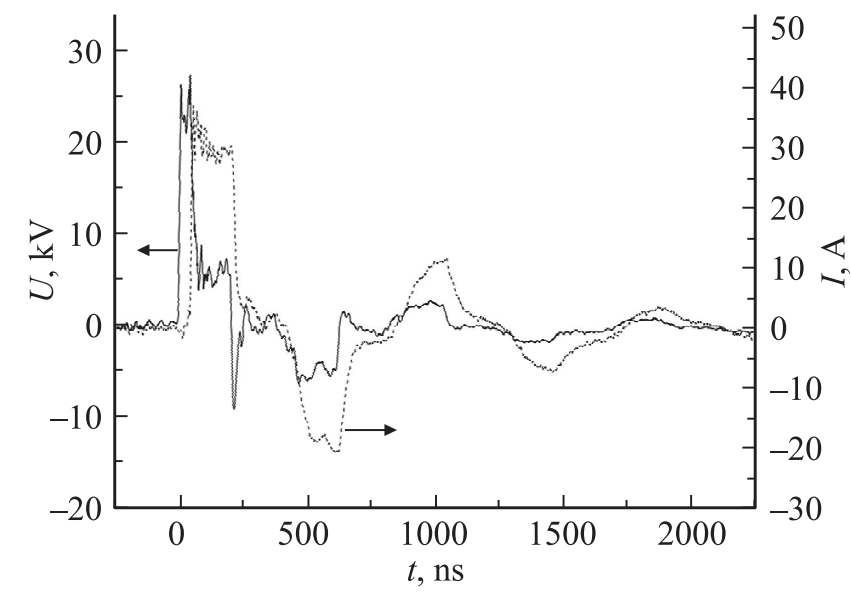

Рис. 2. Осциллограммы напряжения (сплошная кривая) и тока разряда (пунктирная кривая) для положительной полярности острия.

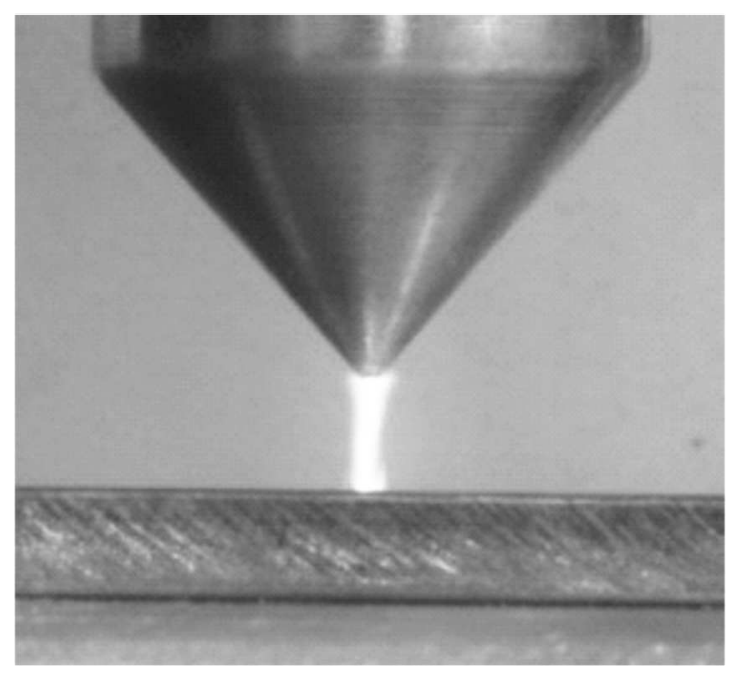

Рис. 3. Фотография свечения разряда.

обеих полярностей не имеет заметных отличий и содержит ярко светящийся центральный керн диаметром $0.3-0.4 \mathrm{~mm}$ и диффузную оболочку диаметром около $1 \mathrm{~mm}$. Аналогичная структура регистрировалась и в других работах при исследовании разряда в промежутках с близкой геометрией [14-16].

Области контакта разрядного канала с поверхностью плоского электрода исследовались с помощью сканирующего электронного микроскопа. При обеих полярностях в указанных областях обнаружены морфологические изменения поверхности электрода в виде округлых пятен или групп пятен. Диаметры отдельных пятен находятся в интервале значений 20-200 $\mu \mathrm{m}$. На рис. 4 представлено изображение группы из шести пятен, образованных в результате воздействия канала разряда положительной полярности. Данное электронно-микроскопическое изображение получено в режиме детектирования вторичных электронов.
На изображении видны также неоднородности поверхности электрода в виде границ зерен его материала и следов полировки. Анализ массива полученных изображений позволяет сделать вывод об отсутствии тенденции привязки пятен к указанным неоднородностям.

Все пятна имеют хорошо различимую пространственную структуру в виде совокупности концентрических колец, что иллюстрирует рис. 5 , где для одного и того же пятна представлены два его изображения, полученные с использованием разных детекторов. При детектировании вторичных электронов (рис. 5, $a$ ) переход от одного кольца к другому выглядит как смена оттенков серого цвета. При детектировании обратно рассеянных электронов (рис. $5, b$ ) видно, что внутреннюю кольцевую структуру пятен образуют скопления большого количества микрократеров. Это особенно отчетливо видно на изображении этого пятна, снятого с бо́льшим увеличением (рис. 6).

Микрократеры представляют собой углубления с периметром в виде неправильных многоугольников. Глу-

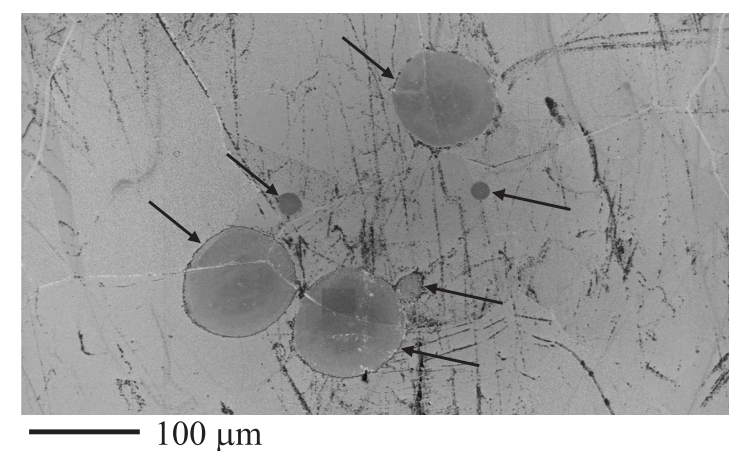

Рис. 4. Электронно-микроскопическое изображение области воздействия разряда на поверхность плоского электрода для положительной полярности острия, полученное на детекторе вторичных электронов. Пятна на изображении указаны стрелками.

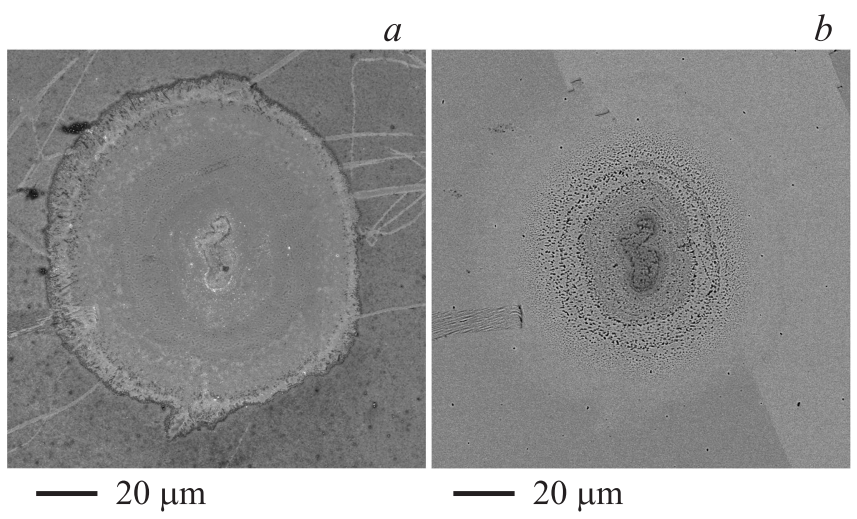

Рис. 5. Электронно-микроскопическое изображение области воздействия разряда на поверхность плоского электрода для положительной полярности острия: $a$ - детектирование вторичных электронов, $b-$ детектирование обратно рассеянных электронов. 


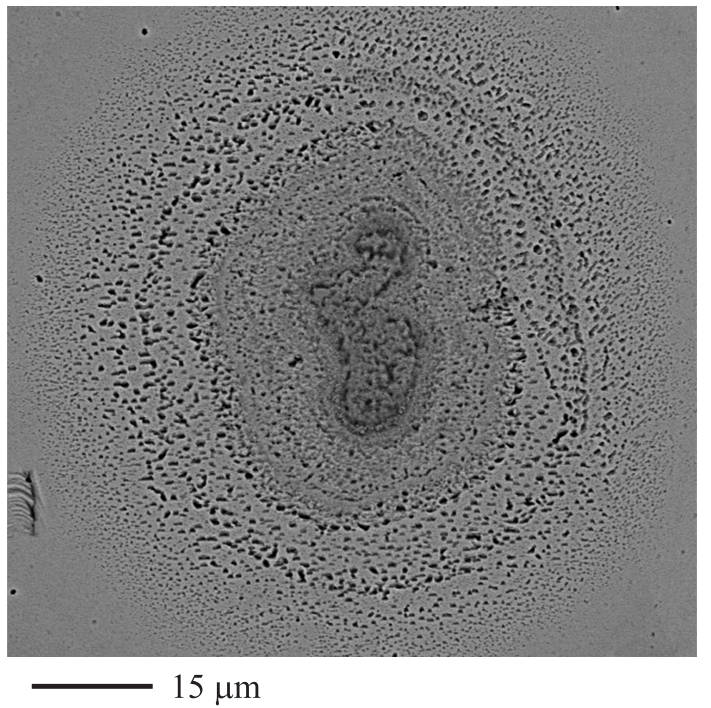

Рис. 6. Электронно-микроскопическое изображение пятна, представленного на рис. $5, b$, снятое с бо́льшим увеличением на детекторе обратно рассеянных электронов.

бина микрократеров сопоставима с их диаметром. Диаметры микрократеров находятся в диапазоне значений 0.1-1 $\mu \mathrm{m}$. По-видимому, микрократеры образовались в результате локального выноса вещества из электрода. При этом на границе микрократеров и в прилегающих к микрократерам областях следов вынесенного вещества не обнаружено. В указанных областях поверхность электрода выглядит так же как и не подверженные воздействию разряда участки.

Микрократеры образуют скопления в форме колец, причем различие колец определяется разной плотностью и/или размером микрократеров в кольцах. Ширина отдельного кольца составляет примерно $3 \mu \mathrm{m}$. На внешнем кольце микрократеры обладают наименьшими диаметрами в пятне, причем размеры микрократеров во внешнем кольце с увеличением расстояния от центра уменьшаются, постепенно сливаясь с фоном. Ширина внешнего кольца составляет около $10-15 \mu \mathrm{m}$.

Следует отметить, что визуализируемый на детекторе AsB диаметр внешнего кольца микрократеров меньше диаметра пятна, полученного детектором InLens в 1.3-3 раза. В центральной области пятна диаметром $10-20 \mu \mathrm{m}$ (на рис. 5, $b$ и рис. 6 это темная область неправильной формы), как правило, наблюдается относительно высокая эрозия электрода, так что отдельные микрократеры становятся слабо различимыми.

По результатам обработки массива изображений были определены характерные значения параметров микроструктуры пятен для обеих полярностей острия. Так, диаметр микрократеров $l$ составляет $0.1-1 \mu \mathrm{m}$, расстояние между центрами ближайших микрократеров $L$ равно $0.2-2 \mu \mathrm{m}$, поверхностная концентрация микрократеров $\rho_{N}$ принимает значения $5 \cdot 10^{4}-2 \cdot 10^{6} \mathrm{~mm}^{-2}$.
Следует отметить, что полученные значения $l$ и $L$ заметно меньше, а $\rho_{N}$ существенно превосходит аналогичные величины, полученные в результате воздействия разряда на плоский электрод, изготовленный из нержавеющей стали марки 316L [17] при прочих схожих условиях экспериментов. При этом значительно отличается и форма микрократеров, а также морфология автографа в целом. Так, в отличие от результатов настоящих исследований в [17] микрократеры представляют собой углубления полусферической формы в центральной области и кольцевые полусферические валики на периферии. Также на периферии некоторых микрократеров видны каплевидные выбросы материала электрода [17]. Кроме того, на поверхности медного электрода отсутствуют дорожки, обнаруженные в [17], в то время как на поверхности электрода из нержавеющей стали не наблюдалась кольцевая структура в автографах разряда.

Поскольку определяющим отличием в условиях сравниваемых экспериментов является использование разных материалов плоских электродов, причем проводимость и коэффициент теплопроводности нержавеющей стали значительно ниже, чем для меди, можно предположить, что именно эти параметры определяют столь сильное различие микроструктуры разрядных автографов.

\section{Заключение}

Исследована микроструктура областей воздействия токового канала на поверхность плоского медного электрода при искровом разряде в воздухе атмосферного давления в промежутке „острие-плоскость“ как для положительной, так и для отрицательной полярности острия.

Установлено, что при обеих полярностях области воздействия представляют собой округлые пятна или группы пятен с диаметрами отдельных пятен от 20 до $200 \mu \mathrm{m}$. Пятна обладают внутренней пространственной структурой в виде совокупности концентрических колец. Кольцевую структуру образуют скопления микрократеров, причем различие отдельных колец определяется разной плотностью и/или размером микрократеров в кольцах.

Обнаружено, что микрократеры представляют собой углубления с периметром в форме неправильных многоугольников. Диаметры микрократеров составляют $0.1-1 \mu \mathrm{m}$, их поверхностная концентрация варьируется от пятна к пятну и принимает значения $5 \cdot 10^{4}-2 \cdot 10^{6} \mathrm{~mm}^{-2}$.

Выполнено сравнение полученных данных с результатами других подобных исследований. 


\section{Список литературы}

[1] Мик Джс., Крэгс Джс. Электрический пробой в газах. М.: Иностранная литература, 1960. 606 с.

[2] Райзер Ю.П. Физика газового разряда. М.: Наука, 1987. $592 \mathrm{c}$.

[3] Месяи, Г.А. Импульсная энергетика и электроника. М.: Наука, 2004. 704 c.

[4] Королев Ю.Д., Месяи Г.А. Автоэмиссионные и взрывные процессы в газовом разряде. Новосибирск: Наука, Сибирское отделение, 1982. $252 \mathrm{c}$.

[5] Балданов Б.Б. // Прикладная физика. 2012. № 1. С. 64-67.

[6] Автореф. канд. дис. Лай Гуйю. М.: МИФИ, 2004.

[7] Репьев А.Г., Репин П.Б., Покровский В.С. // ЖТФ. 2007. Т. 77. Вып. 1. С. 56-62.

[8] Репин П.Б., Репьев А.Г. Исследование пространственной структуры токовых каналов высоковольтного диффузного разряда в промежутке проволочка-плоскость. Сб. науч. тр. / Под ред. В.Д. Селемира, А.Е. Дубинова. Саров: ФГУП РФЯЦ-ВНИИЭФ, 2003. С. 143-172.

[9] Буранов С.Н., Горохов В.В., Карелин В.И., Павловский А.И., Репин П.Б. // Квант. электрон. 1991. Т. 18. Вып. 7. С. 891-893.

[10] Буранов С.Н., Горохов В.В. и др. Микроструктура токовых каналов и убегание электронов в высоковольтных диффузных разрядах атмосферного давления. Исследования по физике плазмы: Сб. науч. тр. / Под ред. В.Д. Селемира, А.Е. Дубинова. Саров, 1998. С. 39-67.

[11] Перминов А.В., Тренькин А.А. // ЖТФ. 2005. Т. 75. Вып. 9. C. 52-55.

[12] Карелин В.И., Тренькин А.А. // ЖТФ. 2008. Т. 78. Вып. 3. C. 29-35.

[13] Karelin V.I., Trenkin A.A. Runaway Electrons Preionized Diffuse Discharges / Ed. V.F. Tarasenko. Nova Publishers, 2014.

[14] Trenkin A.A., Karelin V.I., Fedoseev I.G. // High Voltage Engineering. 2014. Vol. 40. N 7. P. 2211-2216.

[15] Тренькин А.А., Карелин В.И., Шибитов Ю.М. // Изв. вузов. Физика. 2014. Т. 57. № 12/2. С. 284-289.

[16] Бакит Е.Х., Блинова О.М., Ерофеев М.В. и др. // Физика плазмы. 2016. Т. 42. № 9. С. 859-870.

[17] Карелин В.И., Тренькин А.А., Шибитов Ю.М., Блинова О.М., Ясников И.С. // ЖТФ. 2016. Т. 86. Вып. 10. С. 54 57.

[18] Криштал М.М., Ясников И.С., Полунин В.И., Филатов А.М., Ульяненков А.Г. Сканирующая электронная микроскопия и рентгеноспектральный микроанализ в примерах практического применения (Серия „Мир физики и техники“ II-15). М.: Техносфера, 2009. 208 с. 